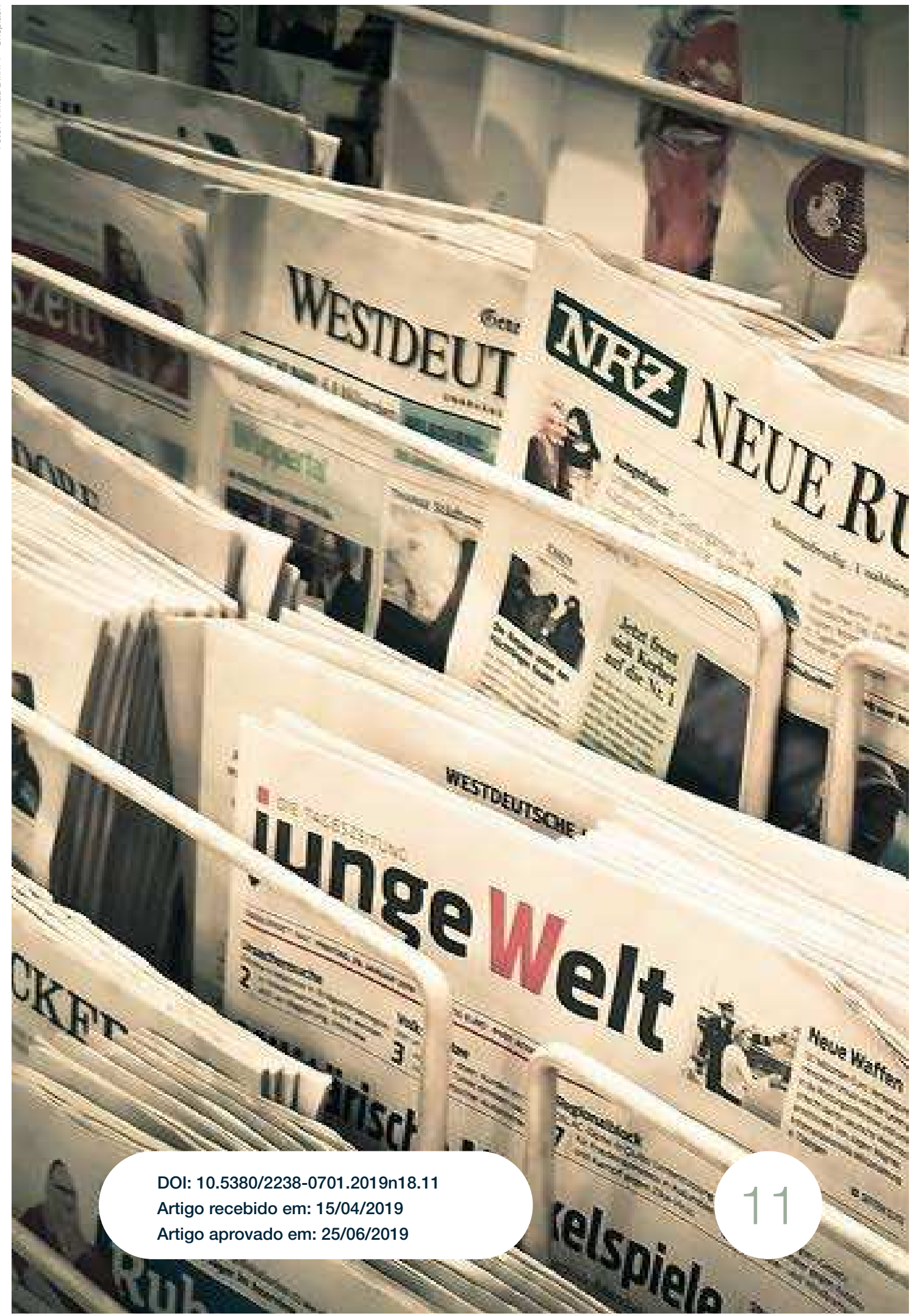


O jornalismo enquanto objeto de estudo 


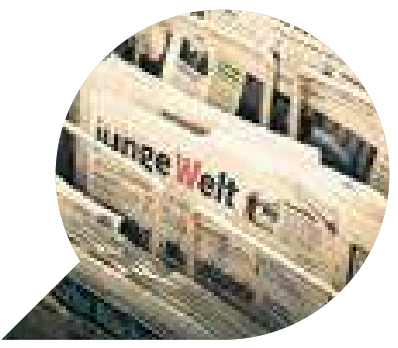

\title{
O jornalismo enquanto objeto de estudo
}

\author{
Journalism as an object of study \\ El periodismo como objeto de estudio
}

POLLYANA DOURADO SANTOS ${ }^{1}$

Resumo: A pesquisa em questão trata-se de um exercício reflexivo sobre a apreensão do objeto de estudo do jornalismo em pesquisas que apresentam o jornalismo apenas como objeto empírico e delimitam sua teoria com conhecimentos de outras áreas do saber. 0 objetivo é realizar uma reflexão sobre o objeto de estudo do jornalismo em intersecção com o campo da comunicação e as múltiplas formas de como se tem trabalhado o jornalismo enquanto objeto empírico. O artigo trabalha com questões que discutem os problemas enfrentados pelas Teorias do Jornalismo, bem como as metodologias utilizadas para analisar o jornalismo enquanto objeto empírico e o silenciamento do jornalismo enquanto objeto de estudo.

Palavra-chave: Teoria do Jornalismo. Objeto de estudo do Jornalismo. Acontecimento. Discurso. Metodologia da Pesquisa em Jornalismo.

1 Doutoranda em Jornalismo pela Universidade Federal de Santa Catarina (POSJOR/UFSC). E-mail: pollyanadourado@hotmail.com. 


\begin{abstract}
The research in question is a reflexive exercise on the apprehension of the object of study of journalism in research that presents it only as an empirical object and delimit its theory with knowledge of other areas of knowledge. The objective is to reflect on the object of study of journalism in intersection with the field of communication and the multiple forms of how journalism has been worked as an empirical object. The article deals with issues that discuss the problems faced by Journalism Theories, as well as the methodologies used to analyze journalism as an empirical object and the silencing of journalism as an object of study.
\end{abstract}

Keywords: Theory of Journalism. Object of study of Journalism. Event. Speech. Methodology of Research in Journalism.

Resumen: La investigación en cuestión se trata de un ejercicio reflexivo sobre la aprehensión del objeto de estudio del periodismo en investigaciones que lo presentan apenas como objeto empírico y delimitan su teoría con conocimientos de otras áreas del saber. El objetivo es realizar una reflexión sobre el objeto de estudio del periodismo en intersección con el campo de la comunicación y las múltiples formas de cómo se ha trabajado el periodismo como objeto empírico. El artículo trabaja con cuestiones que discuten los problemas enfrentados por las Teorías del Periodismo, así como las metodologías utilizadas para analizar el periodismo como objeto empírico y el silenciamiento del periodismo como objeto de estudio.

Palabras clave: Teoría del Periodismo. Objeto de estudio del periodismo. Evento. Discurso. Metodología de la investigación en periodismo.

\title{
Por que pensar em objeto de estudo do jornalismo?
}

Da empiria à teoria, da epistemologia ao jornal, todos esses extremos nos levam a pensar no que seria a pesquisa em comunicação e em que aspectos uma pesquisa em jornalismo se diferenciaria desse campo maior. Para iniciarmos uma reflexão sobre o campo epistêmico do jornalismo, precisamos enumerar alguns problemas enfrentados por 
uma subárea de pesquisa recente, com características peculiares e que é produzida em um contexto geopolítico também singular, o que explica várias implicações, tanto tecnológicas quanto teóricas.

O primeiro deles: o que seria o campo da comunicação e qual seu objeto de estudo.

A Comunicação surge como uma questão tão ampla, tão difusa, tão presente em todas as atividades humanas - que o objeto é de certo modo inapreensível, e conclui-se que 'tudo é comunicação' - a política, a educação, as artes, e uma lista infinda em que se pretendesse abarcar a ação humana e social. (BRAGA, 2001, p. 14).

A comunicação enquanto campo de pesquisa demonstra que existem dificuldades na delimitação de seu objeto de estudo pelas características apresentadas na própria constituição da área como ciência. A partir de Foucault (1972), entende-se que os objetos de estudo são construídos pelos seus especialistas para atender determinada demanda social, do mercado de trabalho ou até para contemplar a especificidade de pesquisas de determinada escola teórica, ou seja, os objetos de estudo refletem as relações de poder estabelecidas por determinada área de pesquisa, seus pesquisadores e a sociedade. De acordo com Dutra (2006, p.219): "O objeto de estudo fala, de certa forma, sobre o pesquisador". Nesse sentido, cabe a seguinte indagação em relação ao campo da comunicação: o objeto são os meios ou as relações intersociais? Há uma concentração das pesquisas em estudo dos meios e seus efeitos no campo da comunicação, fato que tem gerado uma amplitude de temas e recortes que nem sempre estão em diálogo com o campo da comunicação.

A partir do enunciado acima, colocamo-nos diante do segundo problema: e o jornalismo? Existe um campo? Qual seria seu objeto de estudo? Para Groth (2011), o objeto de estudo do jornalismo estaria vinculado às quatro categorias: atualidade, universalidade, publicidade e periodicidade. Ou seja, o objeto de estudo do jornalismo são os jornais e o jornalismo, em que observa-se que o foco se concentra em questões técnicas do jornal, ignorando, portanto, o discurso jornalístico e sua relação de poder com a sociedade. Vejam como Otto Groh compreende a ciência dos jornais: 
Portanto, a Ciência dos Jornais tem a ver de novo com o conteúdo e as suas mudanças e assim Everth procura se salvar do dilema na tautologia e na metáfora: o objeto da Ciência dos Jornais é o que se refere ao jornal. 'O jornal é um vaso que por natureza pode absorver qualquer conteúdo. Por isso, os estudos de jornais têm mais a ver com a forma deste vaso e com a configuração que ele dá respectivamente ao conteúdo do que com o próprio conteúdo em suas inúmeras relações, que são tratadas por outras ciências'. 'Resumindo, o conteúdo do jornal só nos interessa quando se torna conteúdo do jornal. A Ciência dos Jornais trata do que se refere ao jornal no jornal'. (GROTH, 2011, p. 73).

Percebe-se que, para Groth (2011), a ciência dos jornais possui uma "essência" que se concentraria em tudo o que estivesse vinculado ao conteúdo próprio do jornal, da sua materialidade enquanto técnica, por isso a preocupação em citar um autor que compara o jornal a um vaso que dá forma ao conteúdo, ou seja, a ciência dos jornais precisa definir seu objeto de estudo a partir das formas dos jornais, o que explica a intensificação de estudos sobre gêneros jornalísticos, seus formatos tecnológicos e as formas de se escrever nos mais diversos formatos enfatizando a técnica do lead, entre outros aspectos.

Bem diferente de Groth, tem-se Silva (2009 a) que define que o objeto de estudo do jornalismo, além de ser imaterial, é construído historicamente por cada pesquisador e não se limita aos estudos dos meios de comunicação enquanto ferramenta tecnológica:

Objeto de estudo deve ser colocado como uma construção teórica, concebida e alimentada pelos múltiplos objetos nos quais ele se manifesta empiricamente. Por isso a fragilidade epistemológica e teórica quando se localiza o objeto de estudo do Jornalismo exclusivamente nas especificidades de seus produtos materiais, no caso as matérias jornalísticas ou processos produtivos do jornal, revista, telejornal, radiojornal e sítios de notícia. As incontáveis manifestações empíricas do objeto não devem ser tomadas particularmente como o próprio objeto de estudo, este sempre construído teoricamente e maior do que suas expressões materiais. (SILVA, 2009 a, p. 7).

Gislene Silva (2009 a) afirma que o objeto de estudo é delimitado a partir da definição do tema e elaboração do problema de pesquisa, ou seja, é a apreensão teórica construída pelo pesquisador ao investigar determinado objeto, seja ele empírico ou teórico. A autora critica a simples 
utilização do fenômeno empírico analisado como sendo o próprio objeto de estudo, este que é, sempre, uma construção do pesquisador acerca do tema pesquisado e é mais amplo do que sua manifestação empírica, ou seja, a elaboração do objeto de estudo do jornalismo pode e deve ir além de uma simples análise de conteúdo ou de discurso das matérias jornalísticas. Os jornais fazem parte das esferas de poder em sociedade e a extensão de seu poder nem sempre é material. De acordo com Silva (2009 a), o jornalismo enfrenta um problema teórico significativo: as pesquisas sobre os jornais acabam sendo produzidas com teorias de outras áreas científicas e o jornal é utilizado apenas como fonte de pesquisa, o que ela considera ser a causa da fragilidade teórica da área científica do jornalismo. De forma bem parecida, Luiz Martins (2001, p.81) defende: "É preciso que os estudos de comunicação não percam os laços com os dispositivos tecnológicos na base do processo". Em outras palavras, Martins (2001) alerta para que não se confunda o objeto de estudo da comunicação com o próprio veículo de comunicação ou a simples análise destes. O autor alerta ainda para o problema com a interdisciplinaridade na comunicação: interdisciplinaridade é tida como a absorção do referencial teórico de disciplinas mais consolidadas teoricamente nas ciências humanas (sociologia, filosofia e história), ficando da comunicação apenas a análise do objeto empírico.

É difícil ser ouvido quando o objeto da pesquisa é a comunicação. É, no entanto, elaborando os conhecimentos sobre a questão ontologicamente ambígua da comunicação, que conseguiremos talvez criar essa famosa distância crítica indispensável, fonte de toda a liberdade. A função crítica do conhecimento é hoje indispensável à altura do papel da comunicação em nossas sociedades, à velocidade das transformações e ao tamanho dos impérios financeiros que a acompanham. Levando-se a sério os valores e as referências que a comunicação reivindica, podemos analisar e salvar esse conceito, tão essencial ao patrimônio religioso, cultural e político do Ocidente. Quando se reconhecerá que a comunicação é para nossas sociedades uma questão tão importante quanto a educação, a pesquisa, a cidade, a ciência e a saúde. (WOLTON, 2004, p.39).

Partindo da reflexão acima de Wolton (2004), podemos raciocinar da seguinte forma: se a comunicação que é um campo amplo abrangendo três grandes áreas (jornalismo, relações públicas e publicidade) passa pela dificuldade de legitimação e delimitação de seu objeto de estudo, 
pensemos, então, nos desafios enfrentados pelo jornalismo, enquanto campo científico, para conseguir definir as arestas do seu saber, bem como ter sua produção científica reconhecida como necessária para uma vida com relações mais humanizadas e com cidadãos entendidos das relações de poder que envolvem a atividade jornalística.

Nesse sentido, o objetivo principal deste artigo é problematizar a seguinte questão: como apreender metodologias próprias do campo do jornalismo, mesmo que recorrendo aos aportes teóricos de outras disciplinas, sem desprender-se do que há de objetivável no campo específico da comunicação/jornalismo? Esse tem sido um dos principais desafios da pesquisa em comunicação e, sobretudo, da pesquisa que tem o jornalismo enquanto objeto de estudo.

Há indícios de que muitos dos problemas constatados no desenvolvimento de uma Teoria do Jornalismo, no interior da Comunicação como disciplina, também não tenham sido solucionados de maneira mais adequada fora dela, onde o Jornalismo se institucionalizou de forma independente. Tanto no período em que teria vivido esta independência inicialmente (na pré-história da Comunicação), quanto nos locais onde a teria mantido depois e até hoje, os problemas de criação teórico-conceitual específica e de legitimação diante dos campos profissional e acadêmico estiveram e estão presentes (REESE, 1999; REESE \& COHEN, 2000; WEINBERG, 2008). A necessidade de uma Teoria do Jornalismo, e as deficiências no atendimento a esta necessidade pelas Teorias da Comunicação, foram apontadas com propriedade por Genro Filho (1987), entre outros autores, e seguem sendo uma questão ainda não resolvida até o presente, apesar de alguns progressos ocorridos neste sentido no último quarto de século (BENETTI, 2005). Uma causa já identificada é o deslocamento do foco de interesse da teoria produzida na área, que se voltou dos produtos para os efeitos da mídia (REESE, 1999). (MEDITSCH, 2010, p. 101).

Entende-se que o campo científico do jornalismo é uma área ainda recente diante de campos consolidados como o da sociologia, da história, entre outros. Contudo, o jornalismo é estudado enquanto objeto empírico hátempos, basicamente desde o surgimento de todas as ciências humanas e das ciências sociais aplicadas. Recentemente é que autores como Silva (2009 b) e Meditsch (2010) vão reivindicar a concentração da pesquisa em jornalismo a partir da delimitação, não apenas do objeto empírico, mas, sobretudo, do objeto de estudo no campo científico do jornalismo. Meditsch (2010) enfatiza um ponto bem específico do problema referente 
ao desenvolvimento das teorias do jornalismo: há uma concentração de estudo dos efeitos do jornalismo, o que limita a pesquisa da área a extensas descrições empíricas do jornalismo. Além do grande número de pesquisas concentradas apenas na análise das notícias do jornalismo mainstream com o objetivo de otimizar seus produtos jornalísticos, o que deixa, dessa forma, o objeto de estudo do campo do jornalismo, como afirma Silva (2009 b), cada vez mais desconfigurado, silenciado, não identificado e até mesmo sendo confundido com a simples análise do conteúdo ou de discursos das notícias à luz de teorias de outros campos científicos, há pouca concentração em aprimorar o que se entende por teoria do jornalismo e de concentrar esforços no que há de comunicável nos estudos do jornalismo.

Em Costa e Lages (2008) tem-se um clássico exemplo de um dos maiores problemas enfrentados pela comunicação e pelo jornalismo enquanto ciência: a delimitação do objeto de estudo diante de problemas de pesquisa que envolvem outras áreas de saber, ou seja, quando se faz necessária a interdisciplinaridade para a apreensão contextualizada do objeto de estudo. Geralmente, como é o exemplo do artigo citado, o arcabouço teórico se dá em torno do problema social em que se delineia o objeto empírico, enquanto o objeto de estudo da comunicação e do jornalismo não são contemplados, tanto por serem de uma área recente como pela falta de legitimidade teórica diante do campo maior das ciências sociais. Percebe-se, mais uma vez, que o objeto da comunicação é complexo de ser delimitado, em que vários autores apresentam dificuldades em apreender o objeto de estudo da comunicação ao desenvolver determinados conceitos.

Citou-se esse exemplo para elucidar as dificuldades do campo da comunicação em delimitar seu objeto de estudo e enfatizar que tais complicações só aumentam quando afunilamos para o campo específico do jornalismo: desenvolver um conceito ou metodologia oriundos do campo do jornalismo tem sido uma das tarefas mais difíceis a ser realizada pelos pesquisadores da área e é nesse sentido que o artigo procura expor e refletir junto ao leitor sobre tais dificuldades sem nenhuma pretensão de resolver o problema em poucas páginas. Logo, é necessário refletir sobre o trabalho de pesquisadores que se destinam há décadas a individualizar o campo do jornalismo diante do campo mais extenso da comunicação no Brasil, não como uma simples singularidade 
identitária ou legitimação de instituições em detrimento de outras, mas para que haja uma congruência entre o que se analisa e o que se constrói enquanto conteúdo a partir do objeto empírico analisado. Meditsch (2010) busca estabelecer um compromisso em delimitar um objeto de estudo específico para a área:

No campo da produção científica, essa situação criou também uma 'terra de ninguém', que viria a ser ocupada por pesquisadores de outras disciplinas que não a Comunicação, atraídos pela relevância do Jornalismo e pela brecha a ser preenchida. Como observou John Hartley, 'o Jornalismo é a terra nullius da epistemologia, vista por qualquer um que vagueie por ela como um território inabitado do conhecimento, próprio para ser colonizado por qualquer interessado' (HARTLEY, 1996, p. 39). Em consequência, o impulso interdisciplinar recente faz com que o Jornalismo comece a ser levado mais a sério, mas até aí como objeto de estudo de outras áreas que não necessariamente a Comunicação (ZELIZER, 2004). Como campo específico, sua legitimação acadêmica requer ainda a produção de uma teoria própria, que incorpore a produção interdisciplinar dos Journalism Studies para construir conceitos e metodologias próprias, a partir de uma perspectiva necessariamente original (GROTH, 2006). (MEDITSCH, 2010, p. 101-102).

O jornalismo é muito pesquisado por autores como Costa e Lages (2008), em que percebe-se um referencial teórico oriundo da filosofia, da sociologia ou da história, ou seja, em que o jornalismo foi utilizado como um objeto empírico, porque o objetivo era discutir o problema das mudanças climáticas e do desmatamento da Amazônia e não o jornalismo como um objeto de estudo. Mesmo compreendendo o local de fala de contextos sócio-históricos de pesquisas como a de Costa e Lages (2008), compreende-se que uma pesquisa na área de comunicação, como é esta, foge do seu núcleo específico por concentrar seu objeto de estudo em problemas de pesquisa que não são da comunicação, logo, o referencial teórico não dialoga em nenhum momento com o campo da comunicação. Tal situação é muito comum na área por motivos já apontados por Meditsch (2010), que conclui apontando caminhos para uma delimitação do objeto de estudo como pensou Groth (2011). Mesmo que este artigo possua uma perspectiva crítica ao que Groth (2011) definiu como ciência dos jornais, entende-se a importância de seu legado para a delimitação do objeto de estudo do jornalismo e também acrescentase alguns pontos que podem contribuir para complexificar a análise de 
Meditsch (2010):

a) Coube, historicamente, ao jornalismo a condição de objeto empírico por não haver "ciência" ou "teoria" própria que fosse suficientemente capaz de analisá-lo sem o auxílio das ciências sociais: sociologia, história, filosofia, antropologia e a linguística dando um subsídio para teorizar algo que legitimasse o caráter "neutro" de uma possível interpretação textual. Logo, o pensamento jornalístico, ou o que Meditsch (2010) chama de Journalism Studies no século XXI, é algo oriundo de uma preocupação bem delimitada a partir do que Otto Groth propôs no século XX como informa Marhenke (2006);

b) A condição de ciência social aplicada também contribuiu para que a teoria do jornalismo fosse algo pouco estudado ou limitado a assemelhar-se às teorias da comunicação, como é possível observar ao compararmos o que Wolf (2008) chama de teoria da comunicação e o que Traquina (2004) chama de teoria do jornalismo: identifica-se que a teoria do jornalismo em muito se assemelha ao conteúdo das teorias da comunicação aplicada ao objeto empírico do jornalismo. Entende-se que tal fato não se dá aleatoriamente, mas por relações de poder como Foucault (1972) demonstra ao afirmar que a delimitação dos objetos de estudo se dão para legitimar determinados discursos e silenciar outros.

Feitas algumas ponderações sobre o campo do jornalismo e de seus possíveis objetos de estudo, agora serão problematizados um conjunto de artigos que propõem uma análise pragmática do acontecimento enquanto metodologia para analisar jornais.

\section{As dificuldades de desenvolver conceitos próprios do cam- po do jornalismo: sobre acontecimento e discurso}

Há uma tentativa dos pesquisadores, tanto da área da Comunicação (FRANÇA; LOPES, 2017 e SARMENTO; MENDONÇA, 2017) quanto da área do Jornalismo (PONTES; SILVA, 2010), de estabelecer o conceito de acontecimento como sendo um dos objetos de estudo da comunicação 
e do jornalismo enquanto campos específicos de saber. Nos textos que tratam do acontecimento sob um viés da comunicação, percebese a utilização de um intenso aporte teórico de outras disciplinas, sobretudo, das ciências sociais que nos motivam a produzir esta breve reflexão teórico metodológica sobre o jornalismo enquanto subárea da Comunicação Social. Para isso, serão trabalhados o conceito de acontecimento e a análise pragmática deste enquanto operacionalização metodológica nos estudos da comunicação. O objetivo dessa iniciativa não reside em concentrar-se em um estudo de diferenças teóricas entre a perspectiva pragmatista do conceito de acontecimento e a de discurso em um viés pós-estruturalista, por exemplo, mas de explicar algumas das dificuldades de delimitação do objeto de estudo encontradas no interior dos textos sobre metodologia da pesquisa em comunicação.

Para França e Lopes (2017, p. 73), o acontecimento, em uma perspectiva pragmatista, "refere-se a uma ocorrência, um fato concreto do cotidiano com grande poder de afetação, que suscita inquietações, demanda escolhas e provoca ações, este fato convoca e revela sentidos, que dizem da sociedade na qual ela ocorre". Já para Sarmento e Mendonça (2017):

[...] acontecimentos são espécie de permanente tornar-se, que se desdobra no tempo e no espaço, permitindo uma contínua transformação (DELEUZE, 1975). Eles devem ser pensados 'sob as categorias da transição, do vir a ser e da emergência em vez da substância e da simples ocorrência' (QUÉRÉ, 2012, p.22). Diferentemente do 'fato', que delimita um fenômeno para torná-lo reportável, a noção de acontecimento permite pensar o fenômeno em sua complexidade, possibilitando a compreensão de um real que não se estanca. (SARMENTO; MENDONÇA, 2017, p. 844).

O estudo do acontecimento se daria como uma forma de definir uma especificidade do jornalismo, demonstrando suas características e possibilidades de interferência na vida social. Segundo os autores acima, os acontecimentos estão sempre sendo modificados em determinado tempo e espaço. Percebe-se que muitas vezes dá-se o conceito de acontecimento como substituto mais "sofisticado" de jornalismo. Ainda sobre o conceito de acontecimento, os autores acima informam: "Eles criam as condições de sua compreensão ao jogar luz sobre o mundo, permitindo que ele seja reinterpretado, atuando tanto na reelaboração do 
passado como na reestruturação do futuro." (SARMENTO; MENDONÇA, 2017, p. 844-845).

Não seria mais contundente compreender que eles nos dizem sobre determinada luz do mundo? Parece-nos que os autores acima ainda são influenciados por uma perspectiva positivista, mesmo citando Deleuze sem contextualizá-lo e deslocado de todo o referencial teórico da pesquisa citada acima, entendem que os acontecimentos possuem esse "poder" de jogar luz sobre o mundo, como se os acontecimentos refletissem a realidade e não sua representação, como se eles dissessem a verdade dos fatos e não apenas uma perspectiva sobre determinado fato. Quando Sarmento e Mendonça (2017, p. 844) informam que "o conceito propõe-se a viabilizar um viés socioconstrucionista, que não abre mão da existência de um real extra-discursivo", é como se o discurso fizesse parte de algo imaterial, fora da realidade do mundo concreto e que residisse no simples universo de palavras, ou que existisse um real mais material do que o discurso. É como se houvesse o universo material e o discurso residisse em uma esfera oposta, como construção imaginária, para além do real, bem diferente do que propõe Foucault (1972), que nos conduz ao conceito de prática discursiva.

Foucault (1972) rompe com a oposição ideia/matéria quando ele propõe o que ele entende por discurso: os discursos são as práticas discursivas. Não há em Foucault uma divisão entre práxis e ideologia. Foucault (1972) entende que não existe discurso que não seja prática discursiva e que essa divisão só legitima a desigualdade entre aquele que "pensa" e aquele que "trabalha", como se pensar não fosse um trabalho.

O papel do intelectual não é mais o de se colocar 'um pouco na frente ou um pouco de lado' para dizer a muda verdade de todos; é antes o de lutar contra as formas de poder exatamente onde ele é, ao mesmo tempo, o objeto e o instrumento: na ordem do saber, da "verdade", da "consciência", do discurso. É por isso que a teoria não expressará, não traduzirá, não aplicará uma prática; ela é uma prática. (FOUCAULT, 1979, p. 71).

Uma das principais rupturas que Foucault (1972) produz com a dialética hegeliana e a sua apropriação pelo materialismo histórico dialético é essa separação rígida entre o que seria uma ideia e uma prática. Foucault (1979) vai informar porque ele se preocupa tanto com o poder dos intelectuais, porque eles tendem a supervalorizar a teoria 
em detrimento de outras atividades e nega o discurso medieval de que pensar é mais "honrado" do que trabalhar. Para Foucault (1979), a atividade de pensar é material. Percebe-se que para o autor não existe a perspectiva de compreender que o discurso é uma coisa e a prática é outra: os discursos são práticas discursivas, são materialidades também e nisso diferem do conceito de discurso em Pêcheux (1975), Althusser (1987) e em toda a linha de análise do discurso francesa pautada no marxismo que sempre separou infraestrutura de superestrutura.

Em seguida, Sarmento e Mendonça (2017), ao explicarem o conceito de acontecimento em John Dewey, caem novamente na polaridade discurso x realidade: "Dewey acredita que o mundo não é um dado real extra-humano, nem um mero produto de vontades e discursos, mas emerge em um processo transnacional que afeta indivíduos, ao mesmo tempo que é produto deles" (SARMENTO; MENDONÇA, 2017, p. 846). Ao analisar no texto as justificativas feitas para a utilização do conceito de acontecimento para analisar o jornalismo, percebe-se que, para os autores, o discurso e análise do discurso fariam parte desse real "extrahumano" e a análise do acontecimento analisaria só as concreticidades do que entendem por acontecimento. O termo revela bem o objetivo teórico dos autores: o conceito de acontecimento estudaria a materialidade das coisas; enquanto o discurso se deteria a analisar algo do imaginário idealizado sem nenhum compromisso com as condições de enunciação deles. Contudo, percebe-se que há uma indiferença teórica dos estudos do acontecimento citados em relação ao estabelecimento dos poderes em sociedade, o que nos preocupa porque nos leva a interpretações dicotômicas em relação à análise do discurso: os mundos de Platão (real e o ideal); discurso x realidade; língua x ideologia, entre outros.

Enfatizar essas divergências teóricas (nos artigos analisados acima, há uma ênfase na crítica da análise do discurso em detrimento ao estudo do acontecimento como categoria analítica mais eficaz) tornase importante na medida em que compreendemos as dificuldades de consolidação daquilo que seria o objetivo de França e Lopes (2017): fazer do conceito de acontecimento um operador metodológico para os estudos da comunicação. Basicamente, esse tem sido um dos objetivos traçados pela maioria dos pesquisadores de metodologia da pesquisa, sobretudo, daqueles que se concentraram em uma metodologia, geralmente os de análise de discurso ou de conteúdo jornalístico, e que 
procuram desenvolver seus métodos a partir de seu campo específico de estudo, como se percebe em Mazzola e Gregolin (2013), entre outros, que conseguem utilizar uma metodologia própria de seu campo ao analisar determinado objeto empírico. Contudo, percebe-se dificuldades encontradas em França e Lopes (2017) e em Sarmento e Mendonça (2017) de delimitar o que seria próprio da comunicação e o que residiria em um estudo da análise pragmática do acontecimento. Nesse sentido, cabe a pergunta: existe um "acontecimento" que residiria fora do campo científico do jornalismo?

Enunciaremos o conceito de acontecimento a partir do referencial teórico que dialoga com o viés foucaultiano na tentativa de esclarecer algumas lacunas e críticas sobre o que o discurso representa.

Os acontecimentos não são coisas, objetos consistentes, substâncias; eles são um corte que realizamos livremente na realidade, um aglomerado de procedimentos em que agem e sofrem substâncias em interação, homens e coisas. Os acontecimentos não apresentam uma unidade natural; não se pode, como o bom cozinho de Fedro, cortá-los conforme suas articulações, pois eles não as possuem. Por mais simples que ela seja, essa verdade não se tornou conhecida antes do final do século passado e sua descoberta produziu um certo choque; falou-se de subjetivismo, de decomposição do objeto histórico. (VEYNE, 1982, p. 30).

Veyne (1982) afirma que os acontecimentos não são objetos "concretos", cuja materialidade se pudesse medir, quantificar e analisar de forma retilínea e exata, eles são construídos discursivamente pelos enunciadores. São os poderes, sobretudo, que definem o quão material se tornarão as imaterialidades dos acontecimentos ou dos poderes.

[...] gostaria de mostrar que os 'discursos', tais como podemos ouvi-los, tais como podemos lê-los sob a forma de texto, não são, como se poderia esperar, um puro e simples entrecruzamento de coisas e de palavras: trama obscura das coisas, cadeia manifesta, visível e colorida das palavras: gostaria de mostrar que o discurso não é uma estreita superfície de contato, ou de confronto, entre uma realidade e uma língua, o intrincamento entre um léxico e uma experiência; gostaria de mostrar por meio de exemplos precisos, que, analisando os próprios discursos, vemos se desfazerem os laços aparentemente tão fortes entre as palavras e as coisas, e destacar-se um conjunto de regras, 
próprias da prática discursiva. Essas regras definem não a existência muda de uma realidade, não o uso canônico de um vocabulário, mas o regime dos objetos. (FOUCAULT, 1972, p. 64).

Ao analisar contextualmente a reflexão citada, compreenderemos que Foucault (1972) procura explicar que os discursos são permeados pelas relações de poder, que não há separação entre língua e ideologia, entre léxico e experiência, tampouco discurso está relacionado ao "metafísico" ou "extramundo". No trecho acima, Foucault (1972) afirma que, ao analisar os discursos, ele percebia formarem-se um conjunto de regras para a formação dos objetos de estudo, ou seja, em cada discurso ele observava uma série de matrizes de sentido que geravam determinada formação discursiva. Foucault necessita estudar os discursos para compreender as suas relações de poder dentro das suas condições históricas. A proposta de Foucault ao tentar compreender o poder dos discursos era de encontrar, nos mais variados períodos históricos, como esses discursos apresentavam suas regularidades e como eles se materializavam naquilo que Foucault (1972) chamou de práticas discursivas. A reflexão de Foucault evidencia como as práticas discursivas se materializam para disciplinarizar as subjetivações do sujeito, ele afirma que as relações de poder empreendidas a partir de determinadas formações discursivas se materializam nas instituições, no comportamento e nas identidades. O autor compreende que os discursos são práticas discursivas que estabelecem o certo e o errado a partir de suas regras de formação.

Após a explicação do que Foucault (1972) entende por discurso, convém mostrar que assim como Mendonça e Simões (2012) apostam em um diálogo entre a teoria do enquadramento e a proposta teórica da análise do discurso, também se crê que há muito mais diálogos do que confrontos com a análise do acontecimento, como pode ser identificado em Silva e Simões (2014), Silva (2018) e Mazzola e Gregolin (2013), por exemplo. É preciso olhar para além das fronteiras teóricas engessadas pelos campos de pesquisas, sobretudo, quando eles representam determinadas metodologias já consolidadas em certos objetos empíricos. Ao analisarmos uma pesquisa empírica, cujo aporte teórico é feito sob a égide do referencial teórico do acontecimento (SILVA; SIMÕES, 2014) e outra pela proposta foucaultiana de discurso (MAZZOLA; GREGOLIN, 
2013), pôde-se perceber que o resultado das análises em muito se parecem: são encontradas produções de sentidos, leituras sobre determinados recortes de jornais e seus enquadramentos sociais, ou, como prefere Foucault (1972), são identificadas as formações discursivas de cada matéria jornalística analisada, mesmo as que se propõem a fazer uma análise dos acontecimentos, o seu resultado é o mesmo: identificam formações discursivas. Logo, parece-nos que há muito mais diálogos do que fronteiras, por mais que os caminhos teóricos sejam bem distintos, o resultado das análises acaba sendo o de formações discursivas.

Ao percorrer pela bibliografia que trabalha com o conceito de acontecimento, encontra-se ainda Zamin e Marocco (2010) que buscam sistematizar duas vertentes que trabalham com a temática: a exógena e endógena. Para Zamin e Marocco (2010), a exógena refere-se aos estudos que analisam o acontecimento no jornalismo como objeto empírico, mas com o referencial teórico da sociologia, da antropologia e da pedagogia. Enquanto a pesquisa endógena: "reúnem autores que reconhecem os processos de produção, as operações e as práticas jornalísticas que configuram a construção jornalística dos acontecimentos e indivíduos." (ZAMIN; MAROCCO, 2010, p. 105). Nesse sentido, percebe-se que para as autoras, o que seria específico do jornalismo é o que se refere aos paradigmas do newsmaking, ou seja, há uma forte influência em sobrevalorizar um possível "ethos", a partir de um estudo empírico das rotinas produtivas das redações jornalísticas, ou seja, dos processos produtivos das notícias. Ao dizer que a perspectiva endógena é representada pelas pesquisas que reconhecem os processos de produção e as práticas jornalísticas, as autoras nos remetem a referenciais teóricos como Traquina (2004), que afirma a existência de sete teorias do jornalismo (espelho, gatekeeper, organizacional, ação política, construcionista, estruturalista e interacionista), e Traquina (2005), em que o autor se "filia" de forma mais clara ao newsmaking, como tentativa de dar subsídio a uma identidade, um ethos, uma cultura ou como o autor considera, "uma tribo" jornalística que teria o poder de definir o que é e o que não é pauta a partir de dois conceitos chaves para pensarmos a ideia de acontecimento jornalístico: critérios de noticiabilidade e valores notícia.

Esses dois conceitos confrontam-se, fortemente, com a perspectiva que compreende o jornalismo como discurso, pois os critérios de 
noticiabilidade nos dão uma ideia otimista de que cabe ao jornalista o poder de decidir o que é e o que não é importante para a sociedade a partir de valores construídos pelo "ethos jornalístico", entre outras decisões, deixando de lado aquilo que a análise do discurso mais evidencia: a leitura das relações de poder a partir dos recortes dos jornais, que nega, portanto, que o jornalista possua a autonomia de definir o que é ou não notícia.

O estudo do acontecimento no jornalismo é algo complexo e chegase ao ponto de confundir interdisciplinaridade com a separação entre teoria e análise metodológica de determinados objetos empíricos, ficando, assim, a teoria destinada ao campo mais consolidado, e a análise empírica, feita de forma inédita pelo próprio pesquisador, é o que é considerado o conteúdo dos estudos da comunicação. Então, entende-se necessário compreender o conceito de acontecimento, seja ele na comunicação ou no jornalismo, também a partir do local de fala dos teóricos desses respectivos campos.

A principal restrição à ideologia da integração e da compressão cabe em uma só palavra: pode-se comprimir dados, não se pode comprimir nem contextos e nem sentidos. E o problema é ainda mais complicado porque, em uma cultura do instante, o acontecimento interessa mais do que o sentido, a informação mais do que o conhecimento. Mas o acontecimento não leva necessariamente ao saber. Existe então um aumento das dificuldades: não só a hipervalorização do acontecimento não favorece o saber, como a integração das atividades tampouco garante uma melhor administração dessas dificuldades pelo homem. Em outras palavras, o que se ganha em termos de velocidade em integração, de um lado, não se traduz em eficiência do outro. (WOLTON, 2004, p.92).

A partir do trecho acima, percebe-se que Wolton (2004) tem o objetivo de criticar a hipermidiatização dos acontecimentos como sinônimo de comunicação, troca ou até partilha de sentidos como propõe França e Lopes (2017). Para Wolton (2004; 2011), informar não é comunicar, ou seja, há um abismo entre o objetivo da informação e seu real alcance. Muitas vezes a intensidade de acontecimentos transmitidos na mídia promove o que Wolf (2008) chama de disfunção narcotizante, ou seja, ao invés de comunicar com o receptor, de partilhar sentidos, os receptores acabam por filtrar as informações que nem sempre fazem sentido em seu cotidiano ou que simplesmente não concordam com os seus conteúdos, 
gerando, assim, muito mais indiferença do que diálogo. Percebe-se ainda que Wolton (2004) utiliza o termo acontecimento para problematizálo diante de sua construção discursiva e os efeitos que ele, de fato, consegue produzir.

\title{
Da comunicação ao jornalismo: algumas considerações finais
}

No início deste artigo, utilizou-se a reflexão de Braga (2001) para a definição do que seria o campo da comunicação, e Groth (2011) para delimitar o campo do jornalismo, bem como do que seria o objeto de estudo de uma área tão específica, para que pudéssemos, a partir dos problemas teóricos demonstrados, compreender como se constituem as metodologias e métodos aplicados à pesquisa do jornalismo enquanto subárea da comunicação social. Mesmo que pareça tarefa comum, estabelecer os limiares de determinado objeto de estudo específico não tem sido nada simples para áreas recentes como a do jornalismo, como se percebeu nas pesquisas analisadas neste artigo.

Lopes (2003) realiza algumas reflexões sobre o que seria o campo da comunicação a partir do conceito de campo em Bourdieu (1975): o campo seria tudo que envolve a atividade comunicacional (ciência, o ensino e a prática profissional em suas mais variadas clivagens). Para Lopes (2003), o campo científico da comunicação é o que se constitui como objeto de estudo e a autora realiza discussões acerca de sua característica transdisciplinar, entendendo sua formação a partir de um campo de forças entre a relação com as ciências sociais e a disciplinarização da comunicação no Brasil:

\begin{abstract}
É no entroncamento dos processos de institucionalização acelerada dos estudos de comunicação com o crescimento da insatisfação generalizada com a sua disciplinarização no contexto das ciências sociais (Wallerstein) e com a sociedade da comunicação (Vattimo), que se pode identificar a institucionalização transdisciplinar dos estudos da comunicação. (LOPES, 2003, p. 289).
\end{abstract}

De acordo com Lopes (2003), a institucionalização da comunicação enquanto disciplina acadêmica se dá em um contexto de autocrítica das ciências sociais e humanas, então, a comunicação já nasce como uma disciplina em interface com outras áreas de conhecimento, o que a faz 
sempre como esse "aglomerado" de conteúdos, métodos, códigos e normas. Nesse sentido é que a autora entende que o campo científico e seus objetos de estudo são sempre um campo de luta ideológica, nos dizeres de Bourdieu (2004), e por isso se faz necessária a problematização dos usos do jornalismo enquanto objeto empírico em pesquisas de comunicação: há uma imensidão de pesquisas que não possuem um problema de pesquisa voltado ao campo da comunicação, tampouco do jornalismo, mas que utilizam o jornalismo como fonte de pesquisa. Ainda sobre esse aspecto, Lopes (2010) afirma que a metodologia da pesquisa é uma construção elaborada pelo pesquisador a partir do desenvolvimento do seu objeto de estudo, ou seja, ela não está no manual de metodologia científica pronta e preparada para ser aplicada a todos os objetos empíricos recortados por determinado campo de saber, mas constitui-se um exercício que Lopes (2010) chama de reflexividade prática ou social. O processo de reflexividade prática ou social reivindicados por Lopes (2010) nos indicam que a construção do objeto de estudo se dá nessa relação dialógica, tão necessária, entre teoria e empiria, evitando o isolamento entre pesquisador e objeto pesquisado, entre outros aspectos. Lopes (2010) reivindica que a construção do objeto de estudo se dê a partir não do encaixe do modelo metodológico, mas da construção dele pelo próprio pesquisador em confronto com as múltiplas realidades que o objeto empírico lhe propuser. "Deve ser lembrado que uma forte crítica ao normativismo do método, está em introjetar a relação social de investigação numa perspectiva que permita ao pesquisador objetivar e compreender as condições sociais da observação/inquirição do social." (LOPES, 2010, p. 38). Esse ato reflexivo nos proporciona pensarmos que as filiações teóricas nem sempre definem os resultados das análises e, portanto, é necessário, sempre que possível, exercer certa acuidade epistêmica no ato da elaboração teórica, sobretudo, quando diz respeito à legitimação de determinada corrente teórico-metodológica em detrimento de outra, como se houvesse sempre uma linha evolutiva na enumeração das teorias e, assim, uma determinada teoria ou metodologia pudesse ser totalmente superada.

Ao analisar os textos que utilizam uma análise do acontecimento para analisar os jornais, percebe-se uma falta de conteúdos da área específica do jornalismo, parece que o jornalismo é utilizado como simples complemento ou álibi para que se trabalhe com a teoria dos autores da 
análise pragmática do acontecimento, que são sempre os mesmos: França e Lopes (2017); Sarmento e Mendonça (2017); Silva e Simões (2014), todos utilizam Louis Quéré e França (2009) como fundamentação teórica. O problema não reside na interdisciplinaridade, muito pelo contrário, a interdisciplinaridade é benéfica quando não se confunde com utilizar o objeto empírico de uma área e o objeto de estudo de outras áreas mais consolidadas, por exemplo. A interdisciplinaridade não pode servir como desculpa para não se produzir um problema de pesquisa na área específica trabalhada. Interdisciplinaridade tem sido uma das palavras mais problemáticas para a área da comunicação/jornalismo por ser uma área recente, cuja elaboração do objeto de estudo específico demanda investigação inovadora. Convém, ainda, explicitar que ao utilizar o termo "campo" não se reduz ao uso de citações de pesquisadores da área da comunicação para estabelecer rituais estratégicos da profissão ou qualquer outra prática de lobby, mas refere-se à necessidade de produzir conhecimentos da área a que se destina, ou seja, se o jornalismo é utilizado apenas como fonte de pesquisa, que se deixe claro no início do trabalho, caso contrário, abre-se margem para um vazio referente a teorias que sirvam para contemplar a análise dos objetos empíricos que já possuem até uma área específica delimitada, como é o exemplo das ciências dos jornais.

É nesse ínterim que se diluem as dificuldades identificadas no item anterior: a principal é a de definir o que seria próprio do jornalismo, diante dos investimentos teóricos que os pesquisadores da área necessitam realizar para produzirem um saber considerado do "campo da comunicação ou do jornalismo”. Além de ser necessário ainda refletir, a partir da constatação feita por Meditsch (2010) e observada também no resultado de análises de pesquisas como de Costa e Lages (2008) e Silva e Simões (2014), o seguinte aspecto: os estudos que possuem o jornalismo como objeto de estudo, ou que pelo menos precisariam ter, concentram-se em observar os efeitos que os jornais, bem como suas mensagens, suas produções de sentidos, causam na sociedade em que existem. É por conta da concentração em "desvendar" os efeitos dos acontecimentos jornalísticos que as teorias do jornalismo, muitas vezes, são deixadas à margem, por nem sempre atenderem às demandas que o "mercado das interpretações" exige.

O problema da interdisciplinaridade, sem dúvida, é algo evidente 
quando se trata da pesquisa em comunicação e jornalismo; a concentração no estudo dos efeitos, sem dúvida, é um ponto que indica a influência que o capital exerce sobre o interesse da análise política dos discursos na produção e circulação das pesquisas nessa área, entre outros aspectos. Nesse sentido, torna-se pertinente refletirmos sobre o que seria objeto de estudo da comunicação, do jornalismo, suas envergaduras empíricas e teóricas para, então, concentrar esforços no desenvolvimento do campo científico da comunicação. Para além dos efeitos, torna-se necessário compreendermos as especificidades do saber jornalístico não apenas limitado à dicotomia ciência e mercado, como alerta Meditsch (2010), e mais ainda, superando a dicotomia teoria e prática que, provavelmente, é a que mais aflige o campo da comunicação e do jornalismo por conta de todos os motivos explicados no início do artigo. Os textos que analisam o acontecimento como objeto de estudo da comunicação e do jornalismo foram suficientes para nos mostrar o quão complexo é delimitar determinado conceito à luz das teorias da comunicação e do jornalismo, pois eles fizeram uso de teorias oriundas de outras áreas do saber para condensarem seus discursos, silenciando, ainda, os autores da área teórica do jornalismo.

\section{Referências}

ALTHUSSER, Louis. Aparelhos Ideológicos de Estado. 3. ed. Rio de Janeiro: Edições Graal, 1987.

BOURDIEU, Pierre. El ofício del sociólogo. México: Siglo XXI, 1975.

BOURDIEU, Pierre. Os usos sociais da ciência: por uma sociologia clínica do campo científico. São Paulo: Editora UNESP, 2004.

BRAGA, José Luiz. Constituição do campo da comunicação. In: FAUSTO NETO, Antonio; PRADO, José Luiz Aidar; PORTO, Sérgio Dayrrel (Org.). Campos da comunicação: caracterização, problematização e perspectivas. Paraíba: UFPB, 2001.

COSTA, Luciana Miranda; LAGES, Lara Thaís Souza. Mudanças Climáticas e Desmatamento: uma análise do discurso dos jornais Folha de São Paulo e O Globo no contexto da divulgação do relatório final do IPCC em 2007. In: ENCONTRO NACIONAL DA ANPPAS, 4., 2008, Brasília. Anais... Brasília, 2008.

DUTRA, Délia. Reflexões sobre a construção de um problema-e-objeto. In: MALDONATO, Alberto Efendy (Org.). Metodologias de pesquisa em comunicação: olhares, trilhas e processos. Porto Alegre: Sulina, 2006. 
FOUCAULT, Michel. Arqueologia do saber. Petrópolis: Vozes, 1972.

Microfísica do poder. Rio de Janeiro: Edições Graal, 1979.

FRANÇA, Vera; LOPES, Suzana. Análise do acontecimento: possibilidades metodológicas. Matrizes, São Paulo, v. 11, n. 3, p.71-87, set./dez. 2017

LOPES, Maria Immacolata Vassallo de. Reflexividade e relacionismo como questões epistemológicas na pesquisa empírica em comunicação. In: BRAGA, José Luiz; LOPES, M. I. V.; MARTINO, Luiz Claudio (Org.). Pesquisa empírica em comunicação. São Paulo: Paulus, 2010.

LOPES, Maria Immacolata Vassallo de Lopes. Sobre o estatuto disciplinar do campo da comunicação. In: . (Org.). Epistemologia da comunicação. São Paulo: Loyola, 2003. p. 55-67.

MARHENKE, Karl-Ursus. O poder dos jornais, segundo Otto Groth. In: BERGER, Cristha; MAROC$\mathrm{CO}$, Beatriz (Org.). A era glacial do jornalismo: teorias sociais da imprensa. Porto Alegre: Sulina, 2006.

MARTINS, Luiz Claúdio. Interdisciplinaridade e objeto de estudo da comunicação. In: FAUSTO NETO, Antonio; PRADO, José Luiz Aidar; PORTO, Sérgio Dayrrel (Org.). Campos da comunicação: caracterização, problematização e perspectivas. UFPB, 2001.

MAZZOLA, Renan Belmonte; GREGOLIN, Maria do Rosário. A análise do discurso diante de estranhos espelhos: visualidade e (inter)discursividade na pintura. Bakhtiniana, v. 8, n. 2, p. 157-176, jul./dez. 2013.

MEDITSCH, Eduardo. Profissão derrotada, ciência não legitimada: é preciso entender a institucionalização do campo jornalístico. Brazilian Journalism Research, v. 6, n. 1, 2010.

MENDONÇA, Ricardo; SIMÕES, Paula Guimarães. Enquadramento: diferentes operacionalizações analíticas de um conceito. Revista Brasileira de Ciências Sociais, v. 27, n. 79, p. 187-201, jun. 2012.

PÊCHEUX, Michel. Semântica e discurso: uma crítica à afirmação do óbvio. Trad. Eni Orlandi et al. 2 ed. Campinas, SP: Editora da Unicamp, 1975.

PONTES, Felipe Simão; SILVA, Gislene. Acontecimento jornalístico e história. In: BENETTI, Marcia; FONSECA, Virginia Padrelina da Silveira. (Org.). Jornalismo e acontecimento: mapeamentos críticos. Florianópolis: Editora Insular, 2010.

SARMENTO, Rayza; MENDONÇA, Ricardo Fabrino. Luana, Eliza e a Lei Maria da Penha: o acontecimento em discussão. Contemporânea - Comunicação e Cultura, Bahia, v. 15, n. 3, p. 842-865, set./dez. 2017.

SILVA, Gislene. Sobre a imaterialidade do objeto de estudos do jornalismo. Revista E-Compós, Brasília, v. 12, n. 2, maio/ago. 2009 a.

$\overline{2009 b .}$

De que campo do jornalismo estamos falando? Revista Matrizes, ano 3, n. 1, p. 197-212,

SILVA, Gabriela Natália. As muitas faces da prostituição: uma abordagem histórica sobre o controle da sexualidade a partir de Foucault. Divers@. Revista Eletrônica Interdisciplinar, Mantinhos, v. 11, n. 1, p. 15-25, jan./jun. 2018.

SILVA, Terezinha; SIMÕES, Paula Guimarães. Um acontecimento em disputa: sentidos da exuma- 
ção de Jango. Estudos em Jornalismo e Mídia, v. 11, n. 1, p. 34-50, 2014.

TRAQUINA, Nelson. Teorias do jornalismo: porque as notícias são como são. v.1. Florianópolis: Insular, 2004.

Teorias do jornalismo: a tribo jornalística, uma comunidade interpretativa transnacional. v. 2. Florianópolis: Insular, 2005.

VEYNE, Paul. Como se escreve a história: Foucault revoluciona a história. Brasília: EDUNB, 1982. WOLF, Mauro. Teoria da comunicação de massa. 3ed. São Paulo: Martins Fontes, 2008.

WOLTON, Dominique. Pensar a Comunicação. Brasília: Editora da UnB, 2004.

Informar não é comunicar. Porto Alegre: Sulina, 2011.

ZAMIN, Ângela; MAROCCO, Beatriz. Vertentes dos estudos de acontecimento. In: BENETTI, Marcia; FONSECA, Virginia Padrelina da Silveira. (Org.). Jornalismo e acontecimento: mapeamentos críticos. Florianópolis: Editora Insular, 2010. 


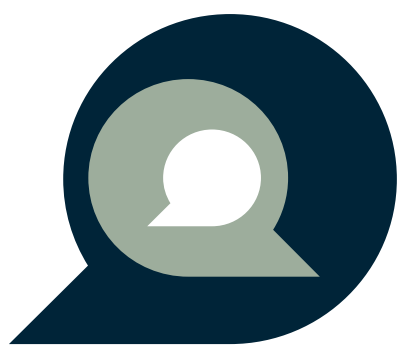

